[Agr. Biol. Chem., Vol. 29, No. 4, p. 275 277, 1965]

\title{
Studies on the Photolysis of Sulfur Containing Compounds in Foods
}

\section{Part II. The Photolysis of 2-Alkyl-Thiazolidine-4-Carboxylic Acids and Mercaptals of L-Cysteine}

\author{
By Yataro Obata and Haruo Tanaka \\ Department of Agricultural Chemistry, Faculty of Agriculture, \\ Hokkaido University, Sapporo.
}

Received August 25, 1964

\begin{abstract}
The aqueous solutions of 2-alkyl-thiazolidine-4-carboxylic acids and mercaptals of $\mathrm{L}$ cysteine were exposed to sunlight in the presence of a small amount of riboflavin. Hydrogen sulfide, ammonia, carbon dioxide and carbonyl compounds were the photolysis products.

As for the carbonyl compounds, formaldehyde and acetaldehyde were identified from thiazolidine-4-carboxylic acid and djenkolic acid, acetaldehyde from 2-methyl-thiazolidine4-carboxylic acid and L-cysteine-mercaptal of acetaldehyde, and acetaldehyde and $n$ butyraldehyde from 2-n-propyl-thiazolidine-4-carboxylic acid and L-cysteine-mercaptal of $n$-butyraldehyde.
\end{abstract}

As previously reported, ${ }^{11}$ S-alkyl-L-cysteines were decomposed by sunlight and evolved volatile compounds such as alkyl mercaptans, acetaldehyde, ammonia and carbon dioxide. These volatile compounds were considered as the cause of the special flavor of the foods containing these S-alkyl-L-cysteines when the foods were exposed to sunlignt. In this report, the authors studied on the behaviors of 2-alkyl-thiazolidine-4-carboxylic acids and mercaptals of L-cysteine to sunlight. In the studies on the factor responsible for blackening of wall of cans containing cooked beef seasoned with soybean protein hydrolyzate, Y. Obata et al. ${ }^{2,3)}$ presumed the presence of heat labile sulfur containing compounds and examined for the heat instabilities of these compounds considered as the precursors of hydrogen sulfide which evolved in the course

1) Y. Obata and H. Tanaka, This Journal. 29, 196 (1965).

2) J. Mizutani, Y. Obata and Y. Ishikawa, Bull. Agr. Chem. Soc. Japan, 24, $382(1960)$.

3) Y. Obata and J. Mizutani, ibid., 24, 562 (1960). of processing, because they founds that the factor for the blackening was hydrogen sulfide in the can." But it has been reported that these compounds were rather stable in boiling aqueous solutions.

The present authors observed that these compounds were easily decomposed and evolved much hydrogen sulfide when the aqueous solutions in the presence of a small amount riboflavin were exposed to sunlight even for a short time. It may be considered that the hydrogen sulfide evolved from the foods containing these sulfur compounds upon exposure to sunlight in the cource of processing before they were canned caused blackening of the can-wall.

In the exposed solutions hydrogen sulfide, ammonia, carbon dioxide and carbonyl compounds were identified.

The identified carbonyl compounds were

4) Y. Obata and S. Sakamura, Y. Ishikawa and J. Mizutani, J. Agr. Chem. Soc. Japan, 31, 585 (1957). 
formaldehyde and acetaldehyde from thiazolidine-4-carboxylic and djenkolic acid, acetaldehyde from 2-methyl-thiazolidine-4-carboxylic acid and L-cysteine-mercaptal of acetaldehyde, and acetaldehyde and $n$-butyraldehyde from 2-n-propyl-thiazolidine-4-carboxylic acid and L-cysteine-mercaptal of $n$-butyraldehyde. These carbonyl compounds were isolated as their 2,4-dinitrophenylhydrazones and identified by paper chromatographies, melting points, elemental analyses and infrared spectra.

It is also considered these volatile compounds generated upon exposure to sunlight are able to cause the representative flavor of the foods.

From these experiments, it was concluded that the photolysis of 2-alkyl-thiazolidine-4carboxylic acids (Reaction 1) and mercaptals of L-cysteine (Reaction 2) proceeded as follows:

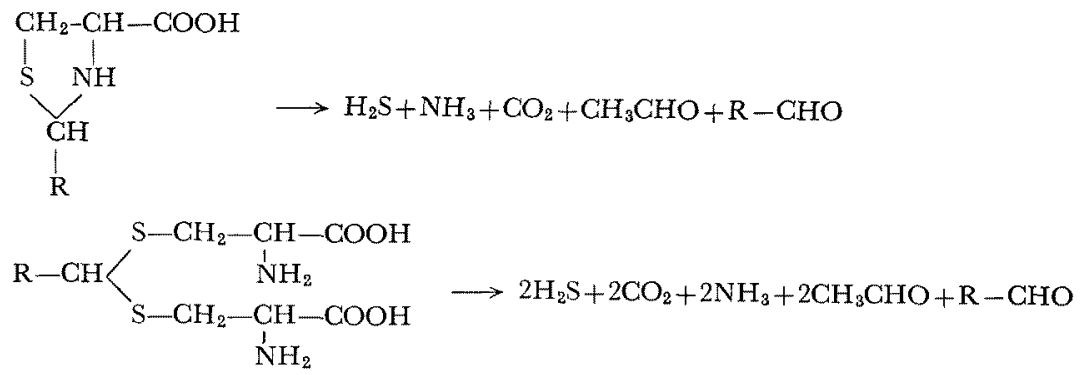

\section{EXPERIMENTAL AND RESULTS}

(I) Preparation of Sample Solutions of 2-AlkylThiazolidine-4-Carboxylic Acids and Mercaptals of L-Cysteine.

Three kinds of 2-alkyl-thiazolidine-4carboxylic acids and of mercaptals of L-cysteine prepared in the previous papers ${ }^{2,3)}$ were used. The photolysis of S-alkyl-L-cysteines has been shown to be acceralated by the addition of riboflavin, ${ }^{1)}$ so this experiment was carried in the presence of a small amount of riboflavin.

2-Alkyl-Thiazolidine-4-Carboxylic Acids.

Each of $500 \mathrm{mg}$ of the compounds was dis- solved in $500 \mathrm{ml}$ of water containing $25 \mathrm{ml}$ of riboflavin.

\section{Djenkolic Acid.}

One hundred milligrams of djenkolic acid monohydrochloride and $50 \mathrm{mg}$ of riboflavin were dissolved in $700 \mathrm{ml}$ of water and adjusted to $\mathrm{pH} 6.8$ with $2 \mathrm{~N} \mathrm{NaOH}$ and then the solution was made to $1,000 \mathrm{ml}$ with water.

\section{L-Cysteine Mercaptan of Acetaldehyde and of} $\boldsymbol{n}$-Butyraldeh yde.

Each of $500 \mathrm{mg}$ of the monohydrochloride compounds and $25 \mathrm{mg}$ of riboflavin were dissolved in $350 \mathrm{ml}$ of water, adjusted to $\mathrm{pH}$ 6.8 and made to $500 \mathrm{ml}$ with water.

(II) Photolysis of 2-Alkyl-Thiazolidine-4-Carbo. xylic Acids and Mercaptals of L-Cysteine.

(1) Identification of Hydrogen sulfide.

Aliquots of $10 \mathrm{ml}$ of the above prepared solutions were placed in individual test tubes, stoppered with corks having a sheet of a
TABLE I. FORMATION OF HYDROGEN SULFIDE FROM THE COMPOUNDS

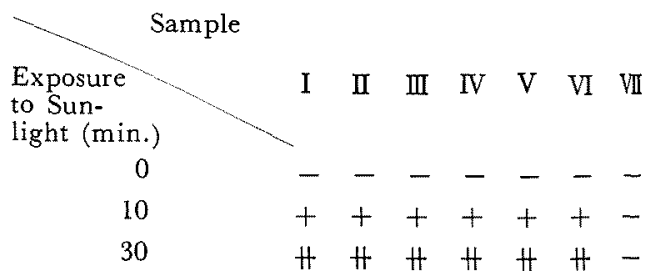

I indicate thiazolidine-4-carboxylic acid, II 2-methyl-thiazolidine-4 carboxylic acid, III 2-n-propyl-thiazolidine-4-carboxylic acid, IV djenkolic acid, V L-cysteine-mercaptal of acetaldehyde, VI L-cysteine-mercaptal of $n$-butylaldehyde and VII riboflavin ( $5 \mathrm{mg}$ per $100 \mathrm{ml}$ of water).

$(-)$ indicates the sign of negative, $(+)$ positive and $(H)$ more definitely recognized. 
lead acetate paper respectively on each center of the cork stoppers and exposed to sunlight on a fine day.

The changing of colors on papers was cheked and organoleptically the ordors of hydrogen sulfide were tested periodically. The results were showen in Table $I$.

(2) Identication of Ammonia and Carbon Dioxide.

Aliquots of $10 \mathrm{ml}$ of the solutions were placed in individual Thunberg tubes and the formed volatile compounds were detected after an hour of exposure; ammonia by the addition of Nesseler's reagent into the exposed solutions and carbon dioxide by the formation of the white precipitates in an aqueous $10 \%$ $\mathrm{Ba}(\mathrm{OH})_{2}$.

(3) Identication of Carbonyl Compounds.

(a) 2-Alkyl-Thiazolidine-4-Carboxylic Acids.

After an aliquot of $350 \mathrm{ml}$ of each solution in individual $500-\mathrm{ml}$ Erlenmeyer flask with a rubber stopper had been exposed to sunlight for three fine days, $150 \mathrm{ml}$ of the 2,4-dinitrophenylhydrazine reagent ${ }^{1)}$ was added to the solutions and the mixture was allowed to stand overnight at room temperature. 2,4-Dinitrophenylhydrazons formed were collected, washed with a small amount of water, dried over phosphorous pentoxide and weighed. Each 2,4-dinitrophenylhydrazone obtained was fractionated using silicic acid-celite column, recrystallized from ethanol and characterized by melting point, paper chromatographic behavior, infrared spectrum as compared with the corresponding authentic sample, and by elemental analysis. The results are summerized in Table II.

(b) Mercaptals of L-Cysteine.

An aliquot of $350 \mathrm{ml}$ of each L-cysteine-
TABLE II. IDENTIFICATION OF CARBONYL COMPOUNDS FROM 2-ALKYL-THIAZOLIDINE-4-CARBOXYLIC ACIDS

\begin{tabular}{|c|c|c|c|c|c|c|}
\hline \multirow{2}{*}{\multicolumn{2}{|c|}{ Sample }} & \multirow{2}{*}{$\begin{array}{c}\text { Yield } \\
(\mathrm{mg})\end{array}$} & \multirow{2}{*}{$\underset{\left({ }^{\circ} \mathrm{C}\right)}{\mathrm{M} \cdot \mathrm{p}}$} & \multirow{2}{*}{$\begin{array}{l}R_{F} * \\
\text { Value }\end{array}$} & \multicolumn{2}{|c|}{ Analysis } \\
\hline & & & & & $\% \mathrm{C}$ & $\% \mathrm{r}$ \\
\hline & F & 55.04 & $159 \sim 60$ & 0.35 & & 3.67 \\
\hline & Ac & & "I & $"$ & & 3.57 \\
\hline & $S$ & 24.32 & $164 \sim 5$ & 0.20 & 40 . & 3.00 \\
\hline & Fo & & $"$ & $"$ & & 2.86 \\
\hline \multirow[t]{2}{*}{ II } & & 98 & $159 \sim 60$ & 0.35 & & 3.68 \\
\hline & $\mathrm{F}$ & 56.87 & $121 \sim 2$ & 0.69 & & 5.00 \\
\hline \multirow[t]{2}{*}{ III } & $\mathrm{Bu}$ & & $n$ & $"$ & 47.62 & 4.76 \\
\hline & & 30.98 & $159 \sim 60$ & 0.35 & 42.85 & 3.76 \\
\hline
\end{tabular}

*: D. F. Meigh, Nature, 170, 579 (1952),

$F$ indicates the fast moving fraction on the column chromatogram and $\mathrm{S}$ slow moving fraction.

Ac indicates the authentic 2,4-dinitrophenylhydrazone of acetaldehyde, Fo that of formaldehyde and Bu that of $n$ butyraldehyde.

The calculated data were shown in the column of Analysis for the corresponding authentic samples.

TABLE III. IDENTIFICATION OF CARbonyl COMPOUNDS FROM MERCAPTALS OF L-CYSTEINE

\begin{tabular}{|c|c|c|c|c|c|}
\hline \multicolumn{2}{|c|}{ Sample } & $\begin{array}{l}\text { Yield } \\
\text { (mg) }\end{array}$ & $\begin{array}{l}\text { M. p. } \\
\left({ }^{\circ} \mathrm{C}\right)\end{array}$ & $\begin{array}{l}R_{F} \\
\text { Value }\end{array}$ & $\begin{array}{l}\text { Species of Aldehyde } \\
\text { Identified }\end{array}$ \\
\hline \multirow{2}{*}{ IV } & F & 24.71 & $159 \sim 60$ & 0.35 & Acetaldehyde \\
\hline & S & 14.55 & $164 \sim 5$ & 0.20 & Formaldehyde \\
\hline V & & 82.6 & $159 \sim 60$ & 0.35 & Acetaldehyde \\
\hline VI & $\mathrm{F}$ & 61.16 & $121 \sim 2$ & 0.69 & $n$-Butyraldehyde \\
\hline VI & $\mathrm{S}$ & 32.54 & $159 \sim 60$ & 0.35 & Acetaldehyde \\
\hline
\end{tabular}

mercaptal of acetaldehyde or $n$-butyraldehyde was placed in individual 500-ml Erlenmeyer flask and an aliquot of $700 \mathrm{ml}$ of the djenkolic acid solution in 1,000-ml flask. Isolated 2,4-dinitrophenylhydrazones by the method already described were identified by mixing melting points, $R_{F}$ values and IR spetra.

The results are summerized in Table III.

2,4-Dinitrophenylhydrazones from the solution of riboflavin (17.5 $\mathrm{mg}$ per $350 \mathrm{ml}$ of water) were obtained in a trace amount. 